\title{
OPEN A lab-on-a-chip approach integrating in-situ characterization and reactive transport modelling diagnostics to unravel $(\mathrm{Ba}, \mathrm{Sr}) \mathrm{SO}_{4}$ oscillatory zoning
}

Jenna Poonoosamy ${ }^{1 \bowtie}$, Mohamed Mahrous ${ }^{2,3}$, Enzo Curti $^{2}$, Dirk Bosbach ${ }^{1}$, Guido Deissmann ${ }^{1}$ Sergey V. Churakov ${ }^{2,3}$, Thorsten Geisler ${ }^{4} \&$ Nikolaos Prasianakis ${ }^{2}$

The co-precipitation of sulphate minerals such as celestine and barite is widely studied because their formation is ubiquitous in natural and anthropogenic systems. Co-precipitation in porous media results in crystallization of solid solutions yielding characteristics such as oscillatory zoning that are rarely observed in bulk solution or in batch experiments. In the past, the precipitation of compositionally-zoned $(\mathrm{Ba}, \mathrm{Sr}) \mathrm{SO}_{4}$ crystals was observed post-mortem in macroscopic silica gel counter-diffusion experiments. Their formation was originally explained by the difference in the solubility products of the end-members combined with diffusion-limited transport of solutes to the mineral-fluid interface, while a later study favored the idea of kinetically controlled reactions. With recent advances combining in-operando microfluidic experiments and reactive transport modelling, it is now possible to verify hypotheses on the driving forces of transport-coupled geochemical processes. We developed a "lab on a chip" experiment that enabled the systematic study of the nucleation and growth of oscillatory-zoned $(\mathrm{Ba}, \mathrm{Sr}) \mathrm{SO}_{4}$ crystals in a microfluidic reactor. The compositions of the solid solutions were determined by in-situ Raman spectroscopy. Our investigation shows (1) that the composition of the nucleating phases can be approximated using classical nucleation theory, (2) that the oscillatory zoning is not solely controlled by the limited diffusional transport of solutes, and (3) that nucleation kinetics plays a major role in the switch between different stoichiometric compositions. The zoning phenomena is governed by the complex interplay between the diffusion of reactants and the crystallization kinetics as well as other factors, e.g. surface tension and lattice mismatch.

Solid solutions including barium sulphate $\left(\mathrm{BaSO}_{4}\right)$ as a major component are widely present in various natural and anthropogenic systems. They are commonly formed during hydraulic fracturing in geothermal systems for energy production ${ }^{1}$, uranium mining tailings ${ }^{2}$ and treatment of industrial waste and contaminated water ${ }^{3-6}$. The low solubility of $\mathrm{BaSO}_{4}$ enables the removal of structure-compatible trace contaminants and radionuclides such as ${ }^{226} \mathrm{Ra}$ and ${ }^{90} \mathrm{Sr}$. In geological repositories for nuclear waste, co-precipitation with $\mathrm{BaSO}_{4}$ solid solutions is expected to reduce the solubility of ${ }^{226} \mathrm{Ra}$, a radionuclide continuously produced by radioactive decay in uranium-bearing waste streams ${ }^{7-10}$, thus limiting its migration towards the biosphere. The high relevance of $\mathrm{BaSO}_{4}$ containing solid solutions as a sink of ${ }^{226} \mathrm{Ra}$ and ${ }^{90} \mathrm{Sr}$ has triggered the development of advanced thermodynamic models that allow to reliably assess the solubility of these radionuclides ${ }^{11,12}$. However, such models are not sufficient to describe the fate of such contaminants in subsurface systems. This is because co-precipitation processes in the porous matrices of the subsurface are typically influenced by the complex interplay of solute transport and dissolution/precipitation kinetics ${ }^{8}$. The relatively slow advective velocities and thus diffusion-dominated transport

${ }^{1}$ Institute of Energy and Climate Research (IEK-6): Nuclear Waste Management and Reactor Safety, Forschungszentrum Jülich GmbH, 52425 Jülich, Germany. ${ }^{2}$ Laboratory for Waste Management, Paul Scherrer Institut, 5232 Villigen PSI, Switzerland. Institute of Geological Sciences, University of Bern, 3012 Bern, Switzerland. "Institut Für Geowissenschaften, Rheinische Friedrich-Wilhelms-Universität Bonn, Bonn, Germany. ${ }^{\boxplus}$ email: j.poonoosamy@fz-juelich.de 
of solutes encountered in various settings in the in the subsurface (e.g. in the engineered barrier system of nuclear waste repositories or in tight rock formations) will induce specific effects during the crystallization of solid solutions which are not or only rarely observed in bulk solution/batch experiments. One such phenomenon is the oscillatory zoning, i.e. the formation of successive layers of minerals with different composition or properties.

Oscillatory zoning is common for binary solid solutions where the solubility products of the end members differ by several orders of magnitude, e.g. $\mathrm{Ba}\left(\mathrm{SO}_{4}, \mathrm{CrO}_{4}\right)$ and $(\mathrm{Ba}, \mathrm{Sr}) \mathrm{SO}_{4}{ }^{13-15}$. Previously, $(\mathrm{Ba}, \mathrm{Sr}) \mathrm{SO}_{4}$ oscillatory zoning (i.e. successive layers of respectively $\mathrm{Sr}$ and $\mathrm{Ba}$ enriched solid solutions) was observed in counter-diffusion experiments ${ }^{16}$. The experimental setup consisted of a porous matrix of silica gel placed between two columns filled with a mixed solution of barium chloride $\left(\mathrm{BaCl}_{2}\right)$ and of strontium chloride $\left(\mathrm{SrCl}_{2}\right)$ solution on one side, and a sodium sulphate $\left(\mathrm{Na}_{2} \mathrm{SO}_{4}\right.$ ) solution on the opposite side. The slow diffusion of solutes through the porous gel triggered the crystallization of zoned $(\mathrm{Ba}, \mathrm{Sr}) \mathrm{SO}_{4}$ crystals. This phenomenon was explained by the alternate consumption of barium $(\mathrm{Ba})$ and strontium $(\mathrm{Sr})$ in the pore solution in contact with the crystallized $\mathrm{Ba}$ and Sr enriched surface layers of the solid solutions, respectively, in a system characterized by slow diffusion of solutes. In principle, the precipitation of the lower solubility end-member (in this case $\mathrm{BaSO}_{4}$ ) was expected to occur first. Nevertheless, the authors also reported a strontium enriched solid solution as first precipitate. They suggested that the nucleation took place under non-equilibrium conditions ${ }^{15}$ with widely different threshold supersaturations for the two components (around 10,000 and 100 for $\mathrm{BaSO}_{4}$ and $\mathrm{SrSO}_{4}$, respectively) that had to be reached for nucleation to occur in the porous gel. The lower threshold for $\mathrm{SrSO}_{4}$ was reached faster and therefore a Sr-enriched solid solution nucleated first. Later, Pina et al. ${ }^{17}$ proposed a "simplified" model based on classical nucleation theory (CNT) to predict the composition of the nucleating phase, but such an approach to predict the composition of the nucleating phase still needs to be verified experimentally. Additional theoretical approaches to describe the phenomenon include cellular automata where Ba and Sr follow a set of rules for their motion and attachment to the crystal surfaces ${ }^{18}$. Such a model implies that the composition of the precipitating phase depends on the solution chemistry and the substrate.

Understanding the mechanisms that drive oscillatory zoning will enable to build realistic conceptual approaches that describe solid solution precipitation and therefore the fate of mobile radionuclides like ${ }^{226} \mathrm{Ra}$ in the subsurface. In this work, we revisit the oscillatory zoning of $(\mathrm{Ba}, \mathrm{Sr}) \mathrm{SO}_{4}$ solid solutions by performing new experiments using a novel micronized lab-on-a-chip device ${ }^{19}$. The device allows carrying out counter diffusion experiments with real-time monitoring of mineral growth by time lapse optical microscopy and in-situ characterization by micro-Raman spectroscopy. The experiments were complemented by reactive transport models, which allow predicting the time-space evolution of transport pathways, aqueous solute concentrations and relevant thermodynamic/kinetic parameters (e.g., saturation indices, precipitation rates). The models are based on lattice Boltzmann methods ${ }^{20,21}$ for the evaluation of the initial stoichiometric saturation ratios in the system and a continuum scale approach to resolve the solute transport coupled to co-precipitation processes ${ }^{22,23}$ and are able to simulate different scenarios that shed light on the key mechanisms responsible for the observed $(\mathrm{Ba}, \mathrm{Sr}) \mathrm{SO}_{4}$ zoning phenomena. In this study, we performed microfluidic experiments and applied and evaluated theoretical approaches (stoichiometric supersaturation function, the delta function ${ }^{15}$ as well a classical nucleation theory extended to solid solutions ${ }^{24}$ ) to predict the composition of the nucleating phase. This enabled us to assess whether the crystal growth zonation is controlled by diffusion of solutes to the mineral-water interface or by crystallization kinetics.

\section{Methods}

Experimental setup and procedure. The experimental setup consists of a microfluidic reactor that is connected to pumps and monitored by optical microscopy and Raman spectroscopy (Fig. 1a). The microfluidic reactor is composed of two adjacent supply channels and 50 growth chambers (Fig. 1b). The growth chambers have a length of $127 \mu \mathrm{m}$ and $60 \mu \mathrm{m}$ width. A narrow channel of $10 \mu \mathrm{m}$ by $10 \mu \mathrm{m}$ connects the supply channels to the growth chambers. The narrow connections between the supply channels and the growth chambers enable a diffusion dominated transport regime in the growth chamber. The barrier structures (Fig. 1d) consist of an array of rectangular pillars (of $7 \mu \mathrm{m}$ length and $2.37 \mu \mathrm{m}$ width) and distanced by $0.6 \mu \mathrm{m}$ placed in the middle of the chamber. They maintain mechanical stability of the chamber and serve as substrate to initiate the nucleation process $^{22}$. The microfluidic reactor was made out of PDMS (Polydimethylsiloxane) and closed with a glass cover.

The two inlets were each connected to a $1 \mathrm{~mL}$ syringe, dispensing a mixed solution of $9.9 \mathrm{mM}^{\circ} \mathrm{SrCl}_{2}$ and $1 \mathrm{mM} \mathrm{BaCl}_{2}$ and a solution of $10.9 \mathrm{mM} \mathrm{Na}_{2} \mathrm{SO}_{4}$, respectively (Fig. 1c). The two outlets were linked to two effluent vessels. The microfluidic reactor was initially filled with deionized water, followed by the injection of the reacting solutions at a rate of $500 \mathrm{~nL} \mathrm{~min}{ }^{-1}$ using a syringe pump (Nemesys, Cetoni GmBH, Germany) for $20 \mathrm{~h}$. The diffusion of the reacting solutions fostered the precipitation of $(\mathrm{Ba}, \mathrm{Sr}) \mathrm{SO}_{4}$ solid solutions in the chambers of the microfluidic device. The experiment was conducted at ambient temperature $\left(21^{\circ} \mathrm{C}\right)$ and pressure.

The microfluidic experiment was monitored using an automated inverted microscope (Witec alpha300 Ri Inverted Confocal Raman Microscope, which consists of an inverted Nikon Ti-2 U as base microscope) with a Nikon 100× oil immersion objective, having a numerical aperture (NA) of 1.25 , a working distance of $0.23 \mathrm{~mm}$, and a cover glass correction. The instrument is equipped with $70 \mathrm{~mW} \mathrm{Nd}$ :YAG laser $(\lambda=532 \mathrm{~nm})$ and a thermoelectrically cooled charge-coupled device (CCD). During the experiment, optical microscopy images of the first 5 chambers were recorded periodically. Time-lapse snapshots of crystal growth were analysed following the approach of Poonoosamy et al. ${ }^{22}$.The images were segmented by colour threshold values chosen manually, based on visual identification of the crystal threshold method in the ImageJ software. The thresholding consisted of segmenting pixels into foreground and background, which resulted in a binary image with the foreground pixels that had a value of one (the solid solution precipitates) and background pixels that had a value of zero. The area with precipitates enabled the calculation of the volume and therefore molar amounts of precipitates. 
(a)
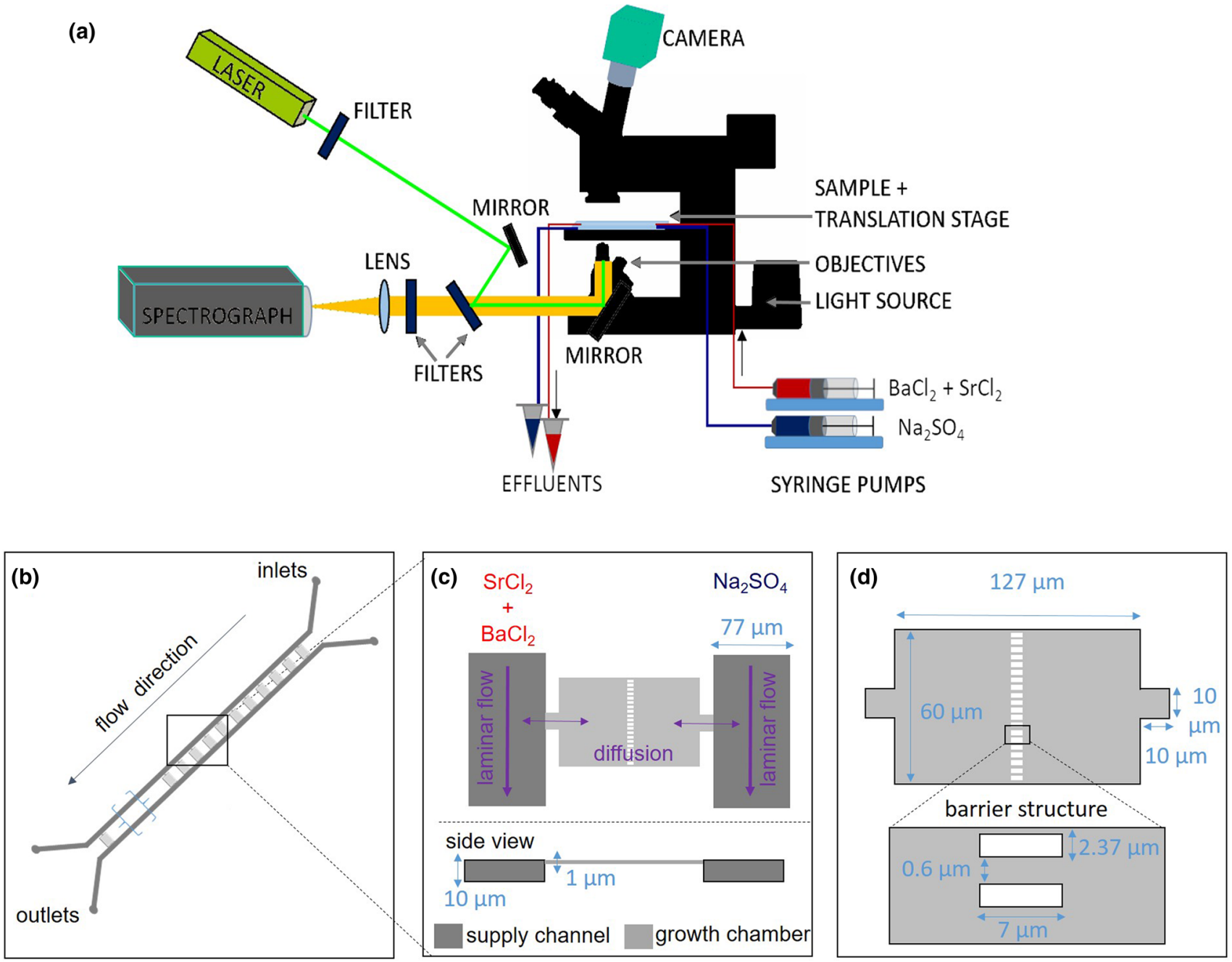

Figure 1. (a) Schematic representation of the microfluidic setup, (b) microfluidic reactor with an array of 50 growth chambers, (c) top view of microfluidic growth chamber with the two adjacent supply channels, (d) an enlargement of the growth chamber with an array of pillars constituting a barrier structure in the middle.

This continuous monitoring allowed determining the apparent initial precipitation rates. After $20 \mathrm{~h}$ of injection, hyperspectral Raman images of the chambers over the region of interest were recorded with a step size of $400 \mathrm{~nm}$ by continuous $\mathrm{x}-\mathrm{y}$ stage movement. Raman intensities were recorded for $0.1 \mathrm{~s}$ in the wavenumber range from 300 to $1300 \mathrm{~cm}^{-1}$. The laser power was set to $50 \mathrm{~mW}$ and a grating with 1800 grooves $/ \mathrm{mm}$ was chosen. With this setup, the spectral resolution was $2 \mathrm{~cm}^{-1}$. The theoretical, diffraction-limited lateral and axial resolutions of the Raman measurements at the sample surface were calculated at $\sim 520 \mathrm{~nm}$ and $2043 \mathrm{~nm}$ using Eq. (3) in 4 in Everall $^{25}$, and considering the refraction index of the immersion medium $(n=1.55)$.

In addition, the Raman spectra of synthetic $\mathrm{BaSO}_{4}$ (99.99\% from Chempur), $\mathrm{SrSO}_{4}(99.99 \%$ from Chempur) and the cured PDMS were collected for $0.4 \mathrm{~s}$ in the wavenumber range from 200 to $1400 \mathrm{~cm}^{-1}$. These measurements served as standards for further evaluation of our experimental data. The free sulphate ions $\left(\mathrm{SO}_{4}^{-2}\right)$ have characteristic $v_{1}$ and $v_{3}$ bands corresponding to the symmetric and the anti-symmetric stretching modes, respectively, and $v_{2}$ and $v_{4}$ bands corresponding to the bending vibrations. The intense $v_{1}\left(\mathrm{SO}_{4}\right)$ band for $\mathrm{BaSO}_{4}$ and $\mathrm{SrSO}_{4}$ are located at 988 and $1001 \mathrm{~cm}^{-1}$, respectively, and thus do not overlap with bands from PDMS. The stoichiometric composition of the solid solutions was determined using the True match module (Witec Control 5.6 Software), which uses an algorithm based on least square fitting to determine the mole percentage of each end-member. In addition, we applied a different methodology based on Vegard's law behaviour observed for sulphate solid solutions, i.e., lattice parameters as well as vibrational frequencies are linearly correlated with composition ${ }^{26}$. This method is based on a linear interpolation of the positions $\left(\mathrm{cm}^{-1}\right)$ of the $v_{1}\left(\mathrm{SO}_{4}\right)$ band maxima as function of the mole fraction of both end members. Both methods gave consistent results and were in agreement with measured Raman spectra of $(\mathrm{Ba}, \mathrm{Sr}) \mathrm{SO}_{4}$ solid solutions standards measured in this work (see supplement S8) and in the literature ${ }^{27}$.

Theoretical approaches. We tested and evaluated well-established theoretical approaches to predict the composition of the nucleating phase based on (1) thermodynamic equilibrium and (2) kinetics. The composition of the thermodynamically most stable solid solution can be determined from the composition of the aque- 
ous solution in a consistent manner either by determining the maximum of the stoichiometric supersaturation function $\left(\Omega_{\mathrm{st}}\right)^{15}$ or the crossing point of the two delta functions $\delta \mathrm{B}$ and $\delta \mathrm{C}^{28}$ (see also supplement S1 and S6). The stoichiometric supersaturation function $\left(\Omega_{\mathrm{st}}\right)$ for solid solutions was computed for the entire compositional range from $\mathrm{X}_{\mathrm{Ba}}=0$ to $\mathrm{X}_{\mathrm{Ba}}=1$ using the equation below ${ }^{15}$ :

$$
\Omega_{s t}\left(X_{\mathrm{Ba}}\right)=\frac{\left(a_{\mathrm{Ba}}{ }^{2+}\right)^{X_{\mathrm{Ba}}}\left(a_{\mathrm{Sr}^{2+}}\right)^{X_{\mathrm{Sr}}}\left(a_{\mathrm{SO}_{4}^{2-}}\right)}{\left(K_{\mathrm{BaSO}_{4}} \gamma_{\mathrm{BaSO}_{4}} X_{\mathrm{Ba}}\right)^{X_{\mathrm{Ba}}} \cdot\left(K_{\mathrm{SrSO}_{4}} \gamma_{S r S O} X_{S r}\right)^{X_{S r}}}
$$

where $a_{B a^{2+}}, a_{S r^{2+}}$ and $a_{S_{4}^{2-}}$ represent the free ion activities in the aqueous solution considering the extended Debye-Huckel ionic strength activity model; $\mathrm{K}_{\mathrm{BaSO}_{4}}$ and $\mathrm{K}_{\mathrm{SrSO}_{4}}$, the solubility products of the end-members $\mathrm{BaSO}_{4}$ and $\mathrm{SrSO}_{4}$ equal to $10^{-9.97}$ and $10^{-6.63} \mathrm{~mol}^{2} \mathrm{~L}^{-2}$ respectively at $298.15 \mathrm{~K}^{29}$; and $X_{B a}$ and $X_{S r}$, the molar fractions of $\mathrm{BaSO}_{4}$ and $\mathrm{SrSO}_{4}$ in the solid. $\gamma_{\mathrm{BaSO}_{4}}$ and $\gamma_{\mathrm{SrSO}_{4}}$ are the activity coefficients of the end-members in the solid solution based on the Thompson-Waldbaum model ${ }^{30}$ and assuming a regular mixing model with a Margules interaction parameter, $w$, of $4950 \mathrm{~J} \mathrm{~mol}^{-111}$. Any solid solution with a stoichiometric saturation $\Omega_{s t}>1$ can potentially precipitate while those with a $\Omega_{s t}<1$ will dissolve. The mole fractions corresponding to the maximum of this function gives the thermodynamically most stable solid solution for a given aqueous solution composition.

Solid solution nucleation kinetics is treated in the framework of classical nucleation theor $y^{24}$. The nucleation rate $J\left(X_{B a}\right)$ for a given solid solution composition $X_{\mathrm{Ba}}$ can be expressed as:

$$
J\left(X_{B a}\right)=\Gamma_{\left(X_{B a}\right)} \exp \left(-\frac{\Delta G_{c\left(X_{B a}\right)}}{k T}\right)
$$

where $k$ is the Boltzmann constant, $T$ is the absolute temperature (298.15 K), $\Gamma$ a pre-exponential factor related to the solubility and $\Delta \mathrm{G}_{\mathrm{c}}$ in the energy required for the formation of a nucleus of critical size. $\Delta \mathrm{G}_{\mathrm{c}}$ is given as:

$$
\Delta G_{c\left(X_{B a}\right)}=\frac{\beta v_{\left(X_{B a}\right)}^{2} \sigma_{\left(X_{B a}\right)}^{3}}{\left(k T \ln \Omega_{s t}\left(X_{B a}\right)\right)^{2}}
$$

where $v_{\left(X_{B a}\right)}$ is the molecular volume of the smallest building unit of the nuclei ("monomer"), $\beta$ is a geometry factor that depends on the shape of the nucleus and was set to 16.8 (value for spheres) $)^{31}$, and $\sigma_{\left(X_{B a}\right)}\left(\mathrm{J} \mathrm{m}^{-2}\right)$ is the effective specific surface energy of the cluster/solution interface and is a linear function of the solid solution composition. The effective specific surface energy for pure $\mathrm{SrSO}_{4}$ and $\mathrm{BaSO}_{4}$ is computed following Eq. 10 of Poonoosamy et al. ${ }^{22}$, considering a contact angle of $65^{\circ}$ for $\mathrm{SrSO}_{4}$ nucleation on $\mathrm{PDMS}^{22}$ and between $21^{\circ}$ to $45^{\circ}$ for the nucleation of a sulphate phase on a sulphate phase (calculated from the effective $\sigma$ of the nucleation of barite on barite ${ }^{32}$ and barite on celestine 33). The surface tension, $\sigma$, of the cluster/solution interface used for pure barite and celestine are 0.134 and $0.092 \mathrm{~J} \mathrm{~m}^{-2}$ respectively ${ }^{31}$. The "monomer" volume was computed by estimating the molecular volumes of the aqueous $\mathrm{BaSO}_{4}(\mathrm{aq})$ and $\mathrm{SrSO}_{4}(\mathrm{aq})$ complexes from the ionic radii of $\mathrm{Ba}^{2+}, \mathrm{Sr}^{2+}$, $\mathrm{S}^{6+}$ and $\mathrm{O}_{2}^{-}$and was considered to be a linear function of the solid solution composition with $8.6 \times 10^{-29} \mathrm{~m}^{3}$ and $8.21 \times 10^{-29} \mathrm{~m}^{3}$ for $\mathrm{BaSO}_{4}(\mathrm{aq})$ (pure barite) and $\mathrm{SrSO}_{4}(\mathrm{aq})$ (pure celestine), respectively.

The pre-exponential factor, $\Gamma$, is given as:

$$
\Gamma_{\left(X_{B a}\right)}=2 \pi Z_{X_{B a}} D N_{0} N_{1} d_{c X_{B a}}
$$

where $D$ is the diffusion coefficient of $\mathrm{BaSO}_{4}(\mathrm{aq})$ and $\mathrm{SrSO}_{4}(\mathrm{aq})$ monomers, which was set to $9.3 \times 10^{-10} \mathrm{~m}^{2} \mathrm{~s}^{-134}$, and $d_{\mathrm{c}}$ the diameter of the critical nucleus, $d_{c}=\frac{4 \sigma_{\left(X_{B a}\right)} v_{\left(X_{B a}\right)}}{k T \ln \Omega} . \mathrm{N}_{1}$ and $\mathrm{N}_{0}$ are the number of monomers per unit volume of fluid and the number of nucleation sites, respectively. $\mathrm{N}_{0}$ was set to $2.5 \times 10^{13} \mathrm{~m}^{-3}$, the same value used by Prieto ${ }^{34}$ for barite. $\mathrm{N}_{1}$ depends on supersaturation and was evaluated by geochemical modelling using GEMS (https://gems.web.psi.ch/) as the sum of $\mathrm{SrSO}_{4}$ and $\mathrm{BaSO}_{4}$ monomers. $\mathrm{Z}$ is the Zeldovich factor given as:

$$
Z_{X B a}=\sqrt{\left(\frac{\Delta G_{c\left(X_{B a}\right)}}{3 \pi k T\left(n_{c X_{B a}}\right)^{2}}\right)}
$$

with the number of monomers in the critical nucleus, $\mathrm{n}_{\mathrm{c}}$, given as:

$$
n_{c X B a}=\left(\frac{2 \sigma_{\left(X_{B a}\right)} a_{X_{B a}}}{3 k T \ln \Omega_{s t\left(X_{B a}\right)}}\right)^{3}
$$

where $a_{X_{B a}}$ is a linear interpolation of the area occupied by a molecule over the compostion, with $a$ equal to $9.42 \times 10^{-19}$ and $9.14 \times 10^{-19} \mathrm{~m}^{2}$ for barite and celestine, respectively.

The crystal growth rate of $(\mathrm{Ba}, \mathrm{Sr}) \mathrm{SO}_{4}$ was evaluated from the experimental datasets of Weber et al. ${ }^{14}$ (see supplement $\mathrm{S} 1$ for further details). The precipitation rate $\mathrm{r}_{(\mathrm{XBa})}\left[\mathrm{mol} \mathrm{s}^{-1}\right]$ for a given stoichiometric composition of $(\mathrm{Sr}, \mathrm{Ba}) \mathrm{SO}_{4}$ follows a second order reaction ( similar to pure barite ${ }^{35}$ ), the kinetic constant, $k_{\mathrm{XBa}}$, of a given stoichiometry can be calculated using the relationship:

$$
r_{(X B a)}=S_{s} k_{X B a}\left(1-\Omega_{s t(X B a)}\right)^{2}
$$


where $S_{\mathrm{s}}$ is the reactive surface area $\left[\mathrm{m}^{2}\right], k_{\mathrm{XBa}}$ is the kinetic constant and evaluated as a linear function of the kinetic constants of the end members with $k\left(\mathrm{SrSO}_{4}\right)$ and $k\left(\mathrm{BaSO}_{4}\right)$ equal to $4.8 \times 10^{-936,37}$ and $1.5 \times 10^{-11} \mathrm{~mol} \mathrm{~m}^{-2} \mathrm{~s}^{-135}$, respectively.

The crystallization rate, $\mathrm{r}_{\mathrm{crys}(\mathrm{XBa})}\left(\mathrm{mol} \mathrm{s}^{-1}\right)$ is defined as the sum of the nucleation rate and crystal growth rate and is given by Eq. (8):

$$
r_{c r y s(X B a)}=\frac{J\left(X_{B a}\right) V n_{c X B a}}{N A}+r_{(X B a)}
$$

where $V$ is the volume in $\mathrm{m}^{3}$ where nucleation can occur, here equal to the volume of the growth chamber and NA is Avogadro's number $\left(6.02 \times 10^{23} \mathrm{~mol}^{-1}\right)$.

Numerical modelling and diagnostics, towards digital twins. For the numerical modelling, several numerical algorithms are used at different steps in order to augment the information that can be extracted from the experiments as well as for the determination of:

(1) The velocity field

The 3D flow field in the growth chamber was simulated with computational fluid dynamics using the software COMSOL Multiphysics 5.3a (COMSOL AB, Stockholm, Sweden see supplement S2); this software was also used to provide a first estimate of solute concentration distributions.

(2) The concentration gradients of the different components, the corresponding geochemical speciation and the saturation indices with respect to the observed precipitates during the initial phase of the experiment

$2 \mathrm{D}$ lattice Boltzmann pore level simulations ${ }^{38}$ were conducted (see references in supplemental material S4: 1,3 ) for the calculation of the transient initial mixing of the solutes in order to resolve the aqueous concentrations of the species within the experimental chambers. The geochemical solver was coupled in a form of a surrogate model, which was trained using machine learning similar to (see references in S4: 2, 3). This provided several orders of magnitude faster calculations compared to the time that would be needed if a geochemical speciation solver would have been coupled directly to the lattice Boltzmann solver. The transient saturation index $S I=\log \Omega$ with respect to the each precipitating phase was calculated until the chemical system reached a mixing steady state, describing the conditions before the first crystallization event occurred (see supplement S4 for more details).

(3) The transport induced solid solution precipitation/evolution of precipitation

1D Open-GeoSys-GEMs (OGS-GEMS ${ }^{39,40}$ ) at the continuum level were conducted to decipher whether the zoning phenomena is a consequence of a diffusion-controlled precipitation or of a kinetically controlled reaction. We conducted two reactive transport studies at the continuum scale: (1) study 1, considering an instantaneous precipitation (thermodynamic equilibrium) of the two predominant solid solution compositions as extracted from the experiments, and (2) study 2 considering the kinetically controlled precipitation. In the continuum model, we projected the experimental setup to a $1 \mathrm{D}$ computational domain of $127 \mu \mathrm{m}$ length and of $60 \mu \mathrm{m}^{2}$ cross-sectional area, setting up a counter diffusion simulation with the same concentration boundary conditions as in the experiments (see supplement S3 for details). The 1D geometry was discretized into a grid composed of elements of $5 \mu \mathrm{m}$ length as well as with a finer mesh discretization composed of finite elements of $1 \mu \mathrm{m}$ length. The advection-diffusion reaction equation (ADRE) (equations S3.1-2 in S3) was solved using the OGS-GEMS code. For the case study 2 , the precipitation rate of the stoichiometric composition was accounted for by crystal growth kinetics only (Eq. 7).

\section{Results}

Crystal growth and compositional zonation. The ingress of the mixed solutions of barium and strontium chloride solutions and sodium sulphate into the microfluidic reaction chambers triggered the formation of euhedral shaped crystals. The crystals were clearly distinguishable after $30 \mathrm{~min}$ reaction time (red circles in Fig. 2a) in the monitored chambers. These crystals occurred at the pillars or at regions of irregularities on the wall of the chambers (blue circle in Fig. 2b). The crystals grew continuously for $400 \mathrm{~min}$, at which time complete clogging of the mass transport pathways was observed, either due to the complete obstruction of the pillars or because of the formation of new crystals at the entrance of the respective growth chamber, preventing further mass exchange between the supply channels and the growth chambers. The crystals appeared to grow by individual layers with alternating Sr-rich and Ba-rich composition, a zonation phenomenon whose boundaries can be observed already by optical microscopy (red arrows in Fig. 2a). The respective composition was resolved by Raman imaging (Fig. 2c) showing the distribution of strontium and barium enriched solid solutions within the single crystals. After the clogging event at the pillars, there was no further exchange of solutes between the two supply channels, therefore the aqueous solution becomes undersaturated with respect to the solids and the crystals dissolve between 600 and $1200 \mathrm{~min}$.

The average Raman spectra of the individual layers were calculated for all crystals in the reaction chambers. Figure 3 shows only those of crystals in chamber 1 and 4 as typical examples. The $v_{1}\left(\mathrm{SO}_{4}\right)$ frequency of all measured spots of the crystals is distinct and intermediate between those of pure $\mathrm{BaSO}_{4}$ and $\mathrm{SrSO}_{4}$, indicating without any doubt the presence of $(\mathrm{Ba}, \mathrm{Sr}) \mathrm{SO}_{4}$ solid solutions. The $v_{1}\left(\mathrm{SO}_{4}\right)$ band was observed at $990 \pm 2,994 \pm 2$ and $1000 \pm 2 \mathrm{~cm}^{-1}$, which correspond to a stoichiometric composition of $\left(\mathrm{Ba}_{0.88} \mathrm{Sr}_{0.12}\right) \mathrm{SO}_{4}$ (green regions), $\left(\mathrm{Ba}_{0.5} \mathrm{Sr}_{0.5}\right)$ $\mathrm{SO}_{4}$ (blue regions) and $\mathrm{Ba}_{0.05} \mathrm{Sr}_{0.95} \mathrm{SO}_{4}$ (red regions), respectively, with an uncertainty in the mole fraction of $\mathrm{Ba}$ of \pm 0.1. $\left(\mathrm{Ba}_{0.88} \mathrm{Sr}_{0.12}\right) \mathrm{SO}_{4}$ was detected only in chamber 1 (crystal 1 at the very early stages, and crystal 3 post 
(a) crystals chamber 1
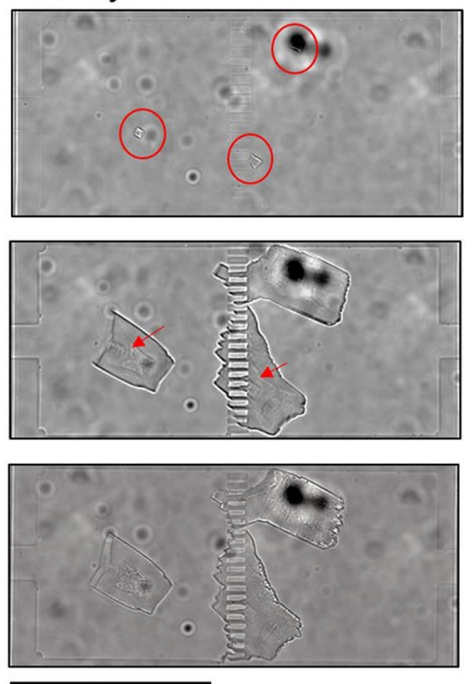

$60 \mu \mathrm{m}$

(c)

\section{Sr enriched} zonation
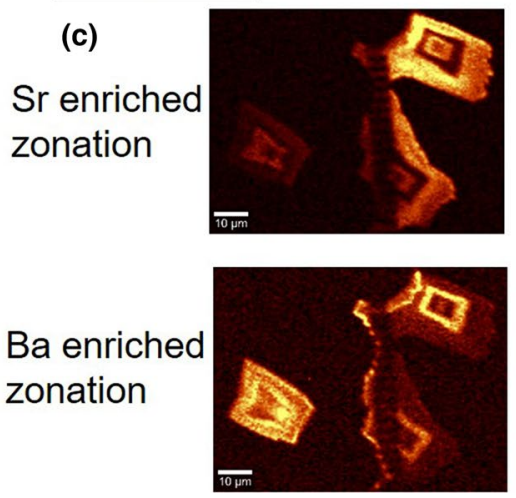

(b) crystals chamber 4

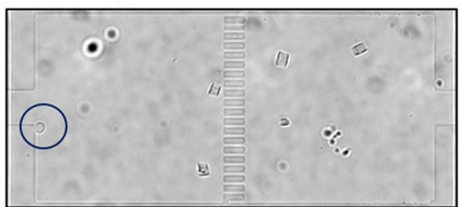

30

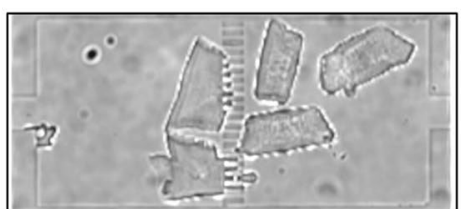

360

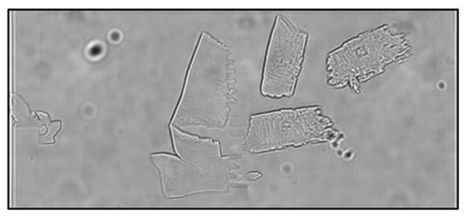

1200

time (minutes)
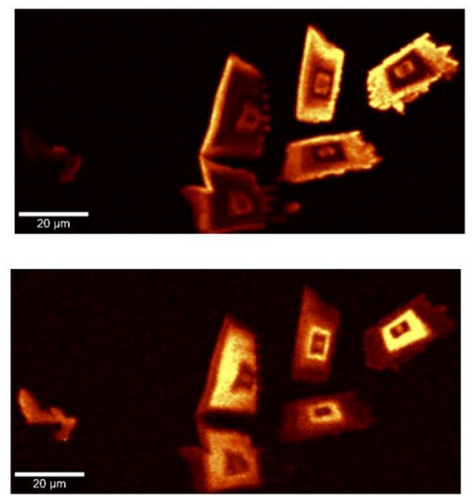

Figure 2. Temporal evolution of crystals in chamber 1 (a) and 4 (b) as revealed by optical microscopy. Image (c) shows hyperspectral Raman images of the $v_{1}\left(\mathrm{SO}_{4}\right)$ intensities from crystals formed after $1200 \mathrm{~min}$ in chamber 1 and 4 with intensities of $1000 \pm 3$ and $994 \pm 3 \mathrm{~cm}^{-1}$.

clogging at the pillars) over a limited region, while all other crystals exhibited a bimodal solid solution composition distribution with alternating compositions $\left(\mathrm{Ba}_{0.5} \mathrm{Sr}_{0.5}\right) \mathrm{SO}_{4}$ and $\mathrm{Ba}_{0.05} \mathrm{Sr}_{0.95} \mathrm{SO}_{4}$.

The crystal growth rates of the individual crystals were calculated from the time lapse images as discussed in the Methods Section (see also supplement S5); the results for chamber 4 are presented in Fig. 4 . The growth rates are more or less constant between 30 and $300 \mathrm{~min}$. Afterwards, as the pathways for solute exchange get obstructed due to the growing crystals, the growth rates for crystals 1,2 and 3 decrease, while no significant change is observed for crystals 4 and 5. Prior to clogging, the average crystallization rates of $\mathrm{Ba}_{0.5} \mathrm{Sr}_{0.5} \mathrm{SO}_{4}$ and $\mathrm{Ba}_{0.05} \mathrm{Sr}_{0.95} \mathrm{SO}_{4}$ of each crystals in chamber 4 were evaluated at $2.9 \pm 0.8 \times 10^{-16}$ and $4.5 \pm 0.8 \times 10^{-16} \mathrm{~mol} \mathrm{~s}^{-1}$, respectively. The total amount of minerals that precipitated per unit time is $1.8 \pm 0.1 \times 10^{-15} \mathrm{~mol} \mathrm{~s}^{-1}$.

Evaluation of the flow field and determination of the dominant mass transport mechanisms with in the growth chamber at steady state. The injection of solutions at constant rate in the supply channels generates a velocity field at steady state as shown in Fig. $5 \mathrm{a}$. The velocity magnitude along the line $y=0$ is depicted in Fig. 5b. It shows that the velocity is highest at $\sim 1.2 \times 10^{-3} \mathrm{~ms}^{-1}$ in the solution supply channels and decreases hyperbolically to $\sim 5 \times 10^{-7} \mathrm{~ms}^{-1}$ in the center of the reactor. The Peclet number $\left(P_{\mathrm{e}}\right.$, defined as the ratio of advective to diffusive transport rates) within the growth chamber was evaluated at 0.01 , after considering a characteristic length of $100 \mu \mathrm{m}$ (i.e. a length over which the velocity is in the same order of magnitude). It can thus be inferred that diffusion dominates the transport of solutes within the growth chamber.

Determination of the local concentrations and saturation indices at the initial stage of the experiment. 2D pore scale lattice Boltzmann simulations were conducted using the exact photographic images. This resulted in a two-dimension lattice grid composed of $245 \times 100$ grid points and a resolution of $0.6 \mu \mathrm{m}$. The time step of the simulation was $\Delta \mathrm{t}=4.28 \times 10^{-5} \mathrm{~s}$. The machine learning accelerated geochemical speciation $^{23}$ was used at every time step and every grid point, thus providing the necessary input for the calculation of the saturation indices. 
(a)

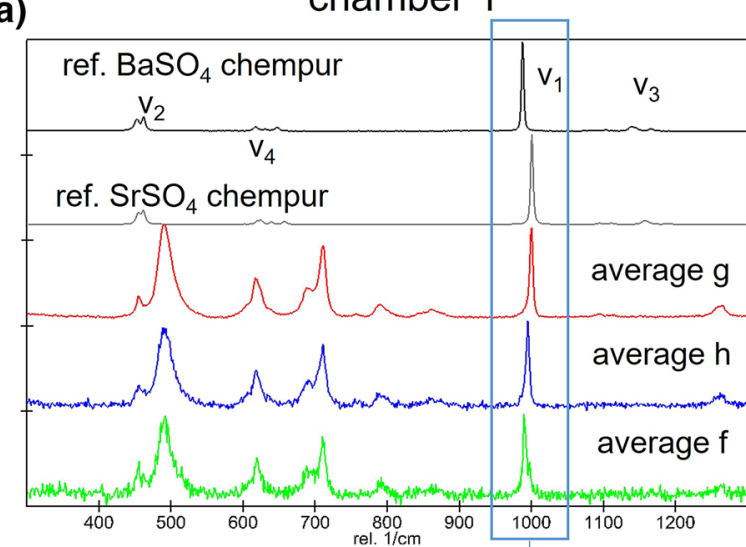

(b)

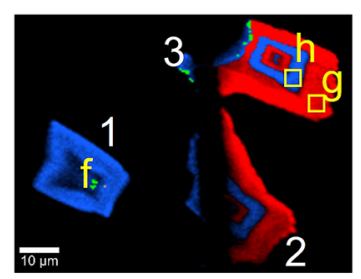

(c)

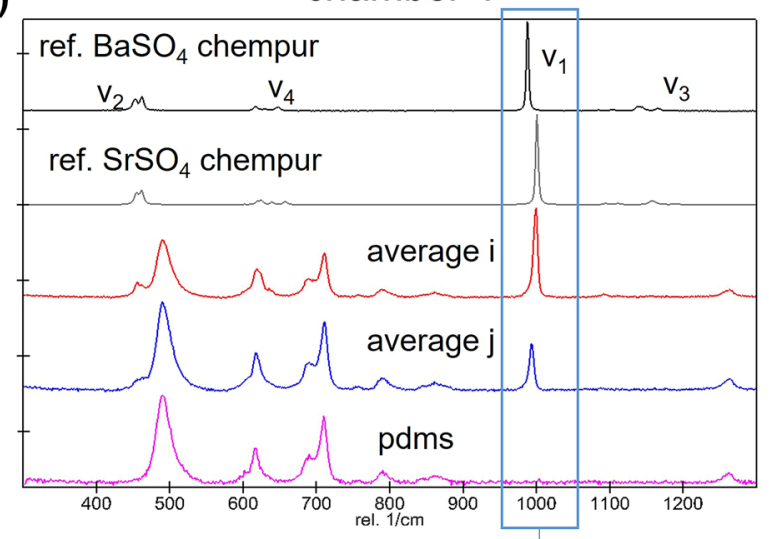

(d)
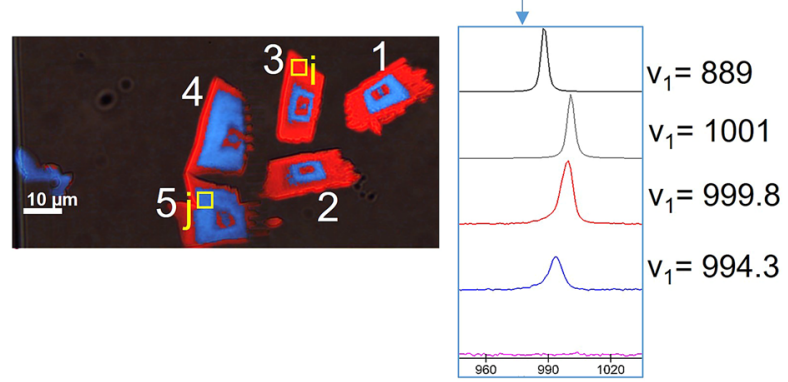

Figure 3. (a) Comparison of the average Raman spectra of the barium (f, h) and strontium (g) enriched layers of selected crystals in chamber 1 and those of commercial 99\% pure $\mathrm{BaSO}_{4}$ and $\mathrm{SrSO}_{4}$, (b) locations where the spectral averaging was done in chamber 1 with an enlargement of the $v_{1}\left(\mathrm{SO}_{4}\right)$ band, (c) comparison of the average Raman spectra of the barium (j) and strontium (i) enriched layers of selected crystals in chamber 4 and those of commercial 99\% pure $\mathrm{BaSO}_{4}$ and $\mathrm{SrSO}_{4}$ and $\mathrm{PDMS}$, (d) locations where the spectral averaging was done in chamber 4 along with corresponding Raman spectra of the $v_{1}\left(\mathrm{SO}_{4}\right)$ frequency region.

The distribution of the concentrations of $\mathrm{BaCl}_{2}, \mathrm{SrCl}_{2}$ and $\mathrm{Na}_{2} \mathrm{SO}_{4}$ at steady state (without precipitation reactions) is shown in Fig. 6. A concentration gradient builds up $30 \mathrm{~s}$ after the start of the injection, with the highest concentrations at the respective supply channel, which decreases to zero in the opposite channel. This concentration gradient reaches a steady state in the absence of chemical reactions. The distribution of $\mathrm{Ba}^{2+}, \mathrm{Sr}^{2+}$ and $\mathrm{SO}_{4}{ }^{2+}$ at the entrance of the growth chambers follows concentric circles which shade off further away from the inlet. Indeed, the solute concentrations do not vary significantly along the y axis for $-50 \mu \mathrm{m}<\mathrm{x}<50 \mu \mathrm{m}$. The simulated SI $(\log \Omega$ ) with respect to the observed precipitating phases are shown in Fig. $6 \mathrm{~d}-\mathrm{f}$, respectively. The saturation ratio for the $\mathrm{Ba}$ rich phase (i.e., $\mathrm{X}=0.88$ and $\mathrm{X}=0.5$ ) is slightly higher in the left compartment of the growth chamber, while the highest saturation ratio with respect to the strontium rich phase occurs in the central part of the growth chamber (Fig. 6g).

Previous work ${ }^{22}$ has shown that the boundary conditions at the entrance of the first five growth chambers vary less than $0.1 \%$. Therefore, we assume the same variation of boundary conditions at the entrance of the first 5 chambers in the present set-up.

Continuum scale modelling of the transport induced precipitation. For a better understanding of the mechanisms that drive the zoning phenomena, we conducted two comparative modelling studies simulating the precipitation of $\mathrm{Ba}_{0.5} \mathrm{Sr}_{0.5} \mathrm{SO}_{4}$ and $\mathrm{Ba}_{0.05} \mathrm{Sr}_{0.95} \mathrm{SO}_{4}$ with two different methods: (1) precipitation assuming instantaneous equilibration (case study 1) and (2) precipitation with kinetic (case study 2) in a simplified 1D geometry, using a continuum-scale reactive transport model solved with OGS-GEMS.

Figure 7a shows the predicted mineral precipitation across the $1 \mathrm{D}$ column for case study 1 and 2, respectively. In case study 1 , both experimentally observed $\mathrm{Ba}_{0.5} \mathrm{Sr}_{0.5} \mathrm{SO}_{4}$ and $\mathrm{Ba}_{0.05} \mathrm{Sr}_{0.95} \mathrm{SO}_{4}$ precipitated. The precipitation starts in the left compartment, where the initial concentrations of $\mathrm{Ba}^{2+}$ and the stoichiometric supersaturation ratio with respect to $\mathrm{Ba}_{0.5} \mathrm{Sr}_{0.5} \mathrm{SO}_{4}$ (Fig. 6) are higher In study 1, continuous re-equilibration between the solid phases and aqueous solution is allowed, which explains the shift in the two maxima between the time 30 and $275 \mathrm{~s}$ in Fig. 7a. The re-equilibration is due to the dissolution of $\mathrm{Ba}_{0.5} \mathrm{Sr}_{0.5} \mathrm{SO}_{4}$ in favour of the precipitation of $\mathrm{Ba}_{0.05} \mathrm{Sr}_{0.95} \mathrm{SO}_{4}$. The sum of the associated rate of precipitation is one order of magnitude higher $\left(3.3 \times 10^{-14} \mathrm{~mol} \mathrm{~s}^{-1}\right)$ than the observed experimental rates $\left(1.8 \pm 0.1 \times 10^{-15} \mathrm{~mol} \mathrm{~s}^{-1}\right)$ (Fig. $\left.7 \mathrm{~b}\right)$. Mesh discretization is known to impact the simulated amounts of minerals that precipitate per unit time ${ }^{40}$. Therefore, we refined the mesh discretization to $1 \mu \mathrm{m}$ and simulated the evolving system for $50 \mathrm{~min}$. Our sensitivity analysis of study 1 (Fig. 7b) showed that the simulated amount of minerals that precipitated per unit time for case study 1 was lower $\left(\sim 7.3 \times 10^{-15} \mathrm{~mol} \mathrm{~s}^{-1}\right)$ in this case, but still higher than the experimental rates. Two major outcomes are 


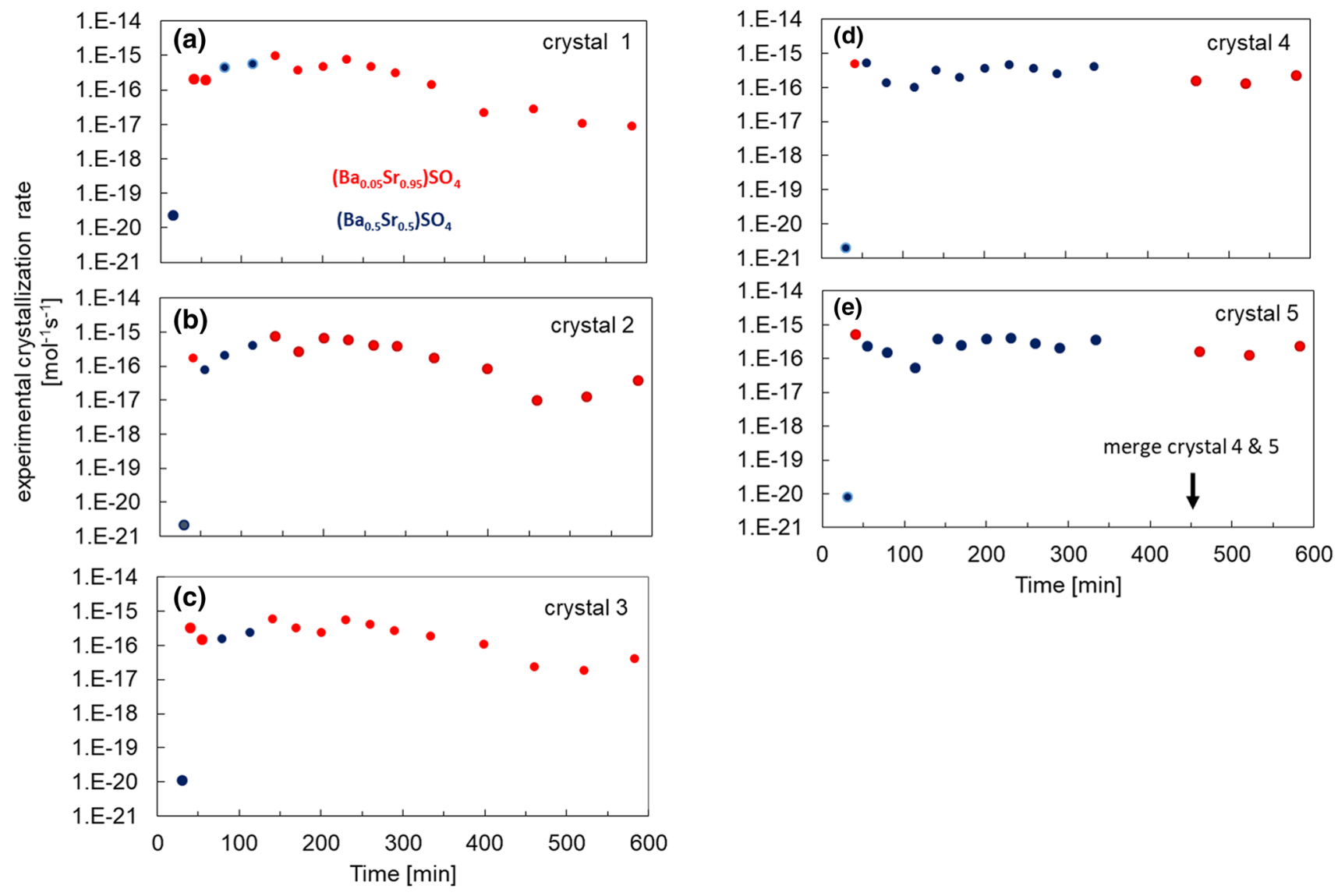

Figure 4. (a-e) experimentally derived crystallization rates of crystals 1-5 in reaction chamber 4.
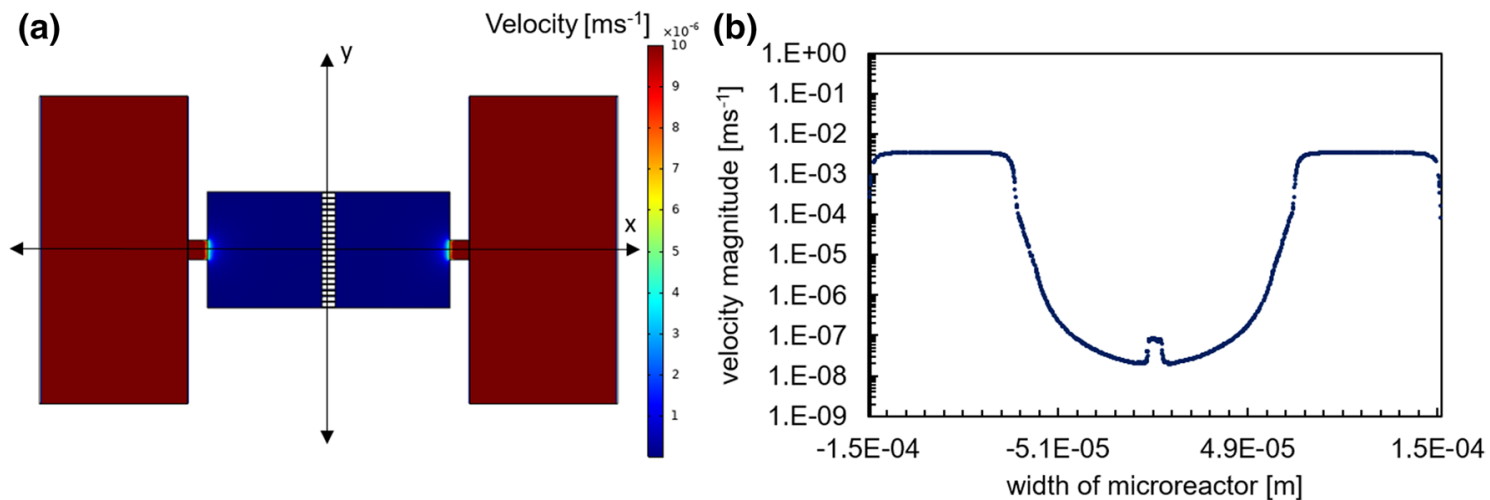

Figure 5. (a) Distribution map of the velocity magnitude at steady state, and (b) profile of the velocity magnitude along line $y=0$ with the center of the growth chamber as origin.

the results of this study. First, for the conditions of the experiment, diffusion coupled with thermodynamic equilibration results in large over prediction of the precipitation rates, verifying that the observed phenomena are not transport (diffusion) limited, and that the interplay of kinetics play a significant role. Second, such a modelling provides not only quantitative, but also qualitative very different results compared to the experimental observations. In contrast to experimental observations, there are no precipitates forming preferentially at the right compartment only.

When the kinetics of precipitation of the two stoichiometric compositions are considered (case study 2), only $\mathrm{Ba}_{0.05} \mathrm{Sr}_{0.95} \mathrm{SO}_{4}$ precipitated in the simulation (Fig. 7a). The precipitation of $\mathrm{Ba}_{0.5} \mathrm{Sr}_{0.5} \mathrm{SO}_{4}$ is kinetically hindered because of the lower kinetic constant of precipitation ( $\sim 1$ order of magnitude). A higher simulated precipitation rate of $\mathrm{BaS}_{0.05} \mathrm{r}_{0.95} \mathrm{SO}_{4}\left(9 \pm 0.1 \times 10^{-15} \mathrm{~mol} \mathrm{~s}^{-1}\right)$ in case study 2 compared to study 1 is observed and explained by the higher saturation ratios that can build up in the system since no other phase precipitates. In case study 2 , the process is rate limited and therefore the mesh discretization between 1 and $5 \mu \mathrm{m}$ has little impact on the amounts of minerals that precipitate per unit time and is therefore not shown here. The applied kinetic model for 
(a)

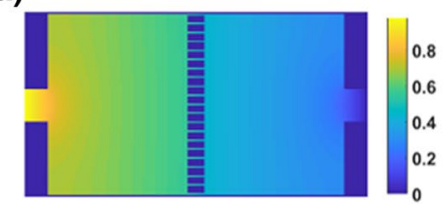

$\mathrm{BaCl}_{2}[\mathrm{mM}]$

(d)

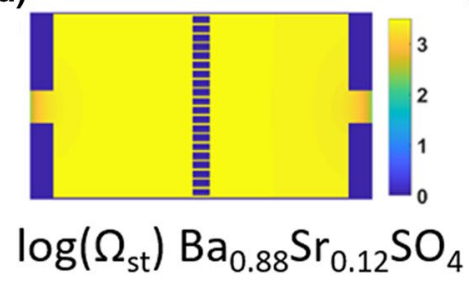

(b)

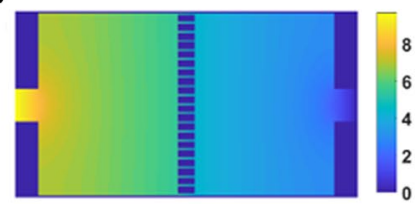

$\mathrm{SrCl}_{2}[\mathrm{mM}]$

(e)

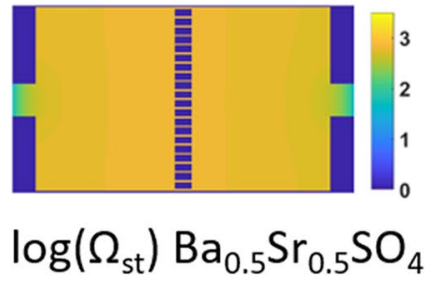

(c)

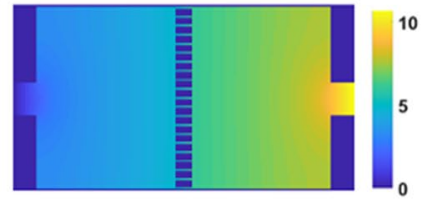

$\mathrm{Na}_{2} \mathrm{SO}_{4}[\mathrm{mM}]$

(f)

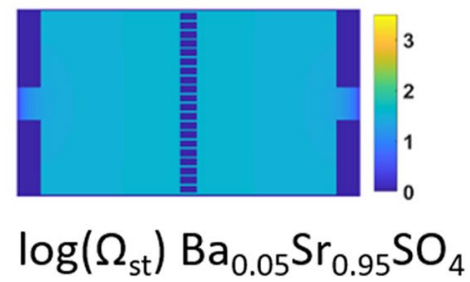

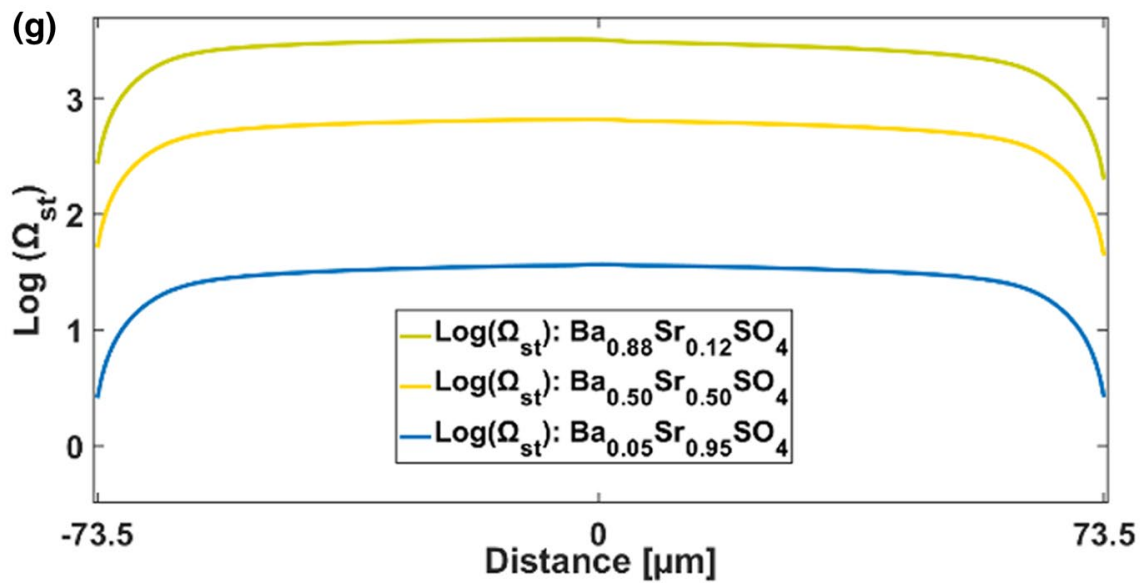

Figure 6. Map of (a) $\mathrm{BaCl}_{2}$, (b) $\mathrm{SrCl}_{2}$ and (c) $\mathrm{Na}_{2} \mathrm{SO}_{4}$ concentrations distributions in the growth chamber and associated stoichiometric supersaturation ratio with respect to (d) $\mathrm{Ba}_{0.88} \mathrm{Sr}_{0.12} \mathrm{SO}_{4},(\mathbf{e}) \mathrm{Ba}_{0.5} \mathrm{Sr}_{0.5} \mathrm{SO}_{4}$ and (f) $\mathrm{Ba}_{0.05} \mathrm{Sr}_{0.95} \mathrm{SO}_{4}$ with their respective plots of stoichiometric saturation ratio profiles along $\mathrm{y}=0$ in $(\mathbf{g})$ for a better visualization.

the precipitation of solid solutions cannot describe our experimental observations but provide better qualitative description of the location of precipitates (i.e. in the middle of the growth chamber).

\section{Discussion}

Composition of the nucleating phase. The stoichiometric composition of the nucleating phase (i.e. of the core of crystallites) in the 5 monitored microfluidic chambers was $\left(\mathrm{Ba}_{0.5} \mathrm{Sr}_{0.5}\right) \mathrm{SO}_{4}$ except for crystal 1 in chamber 1 (see Fig. 4), where a composition of $\left(\mathrm{Ba}_{0.88} \mathrm{Sr}_{0.12}\right) \mathrm{SO}_{4}$ was also observed. Figure 8a reports the frequency of occurrence of the different compositions observed in the crystals during Raman mapping.

The concentrations and activities of $\mathrm{Ba}^{2+}, \mathrm{Sr}^{2+}$ and $\mathrm{SO}_{4}{ }^{2-}$ at the location where the crystallites nucleated were extracted from our lattice Boltzmann simulations (Fig. 6) to calculate the stoichiometric supersaturation functions and associated nucleation rates on the surface of PDMS. Note that the concentrations used for this analysis correspond to the initial stage of the experiment were precipitation is not yet initiated and is used here as a first approximation of the local concentrations after the crystal growth. The results for chamber 4 are shown in Fig. $8 \mathrm{~b}$-e. The supersaturation functions for crystal 2 and 3 practically superpose each other since the aqueous compositions are almost identical (both crystals are located on same $\mathrm{x}$-coordinate value). A similar effect applies to crystals 4 and 5 . The supersaturation functions show that the solution at the nucleation locations is supersaturated with the entire range of possible solid solution compositions $\left(\Omega>1\right.$ for $X_{\mathrm{Ba}}=0$ to 1$)$ and therefore any composition could potentially precipitate. The maxima of these functions lie at $X_{\mathrm{Ba}}=0.99$. This is the solid composition with respect to which supersaturation is highest and it corresponds to true thermodynamic equilibrium with the specific aqueous composition. The computations using the saturation state of the solution using the $\delta$ function gave similar results ${ }^{28}$ (see supplement $\mathrm{S} 6$ for more details). The nucleation rates were computed using classical nucleation theory and the outcome for chamber 4 is presented in Fig. $8 \mathrm{c}$ with the maxima $\left(X_{\mathrm{Ba}}=0.93\right)$ indicating the solid solution composition with the highest probability of nucleation. At thermodynamic equilibrium, a $\left(\mathrm{Ba}_{0.99} \mathrm{Sr}_{0.01}\right) \mathrm{SO}_{4}$ enriched solid solution should precipitate while the kinetic CNT approach suggests nucleation of a Ba-poorer solid with composition $\left(\mathrm{Ba}_{0.93} \mathrm{Sr}_{0.07}\right) \mathrm{SO}_{4}$. However, only once among the 13 analyzed spots a similar composition, $\left(\mathrm{Ba}_{0.88} \mathrm{Sr}_{0.12}\right) \mathrm{SO}_{4}$ with $\left.X_{\mathrm{Ba}} \pm 0.1\right)$ was experimentally observed. 

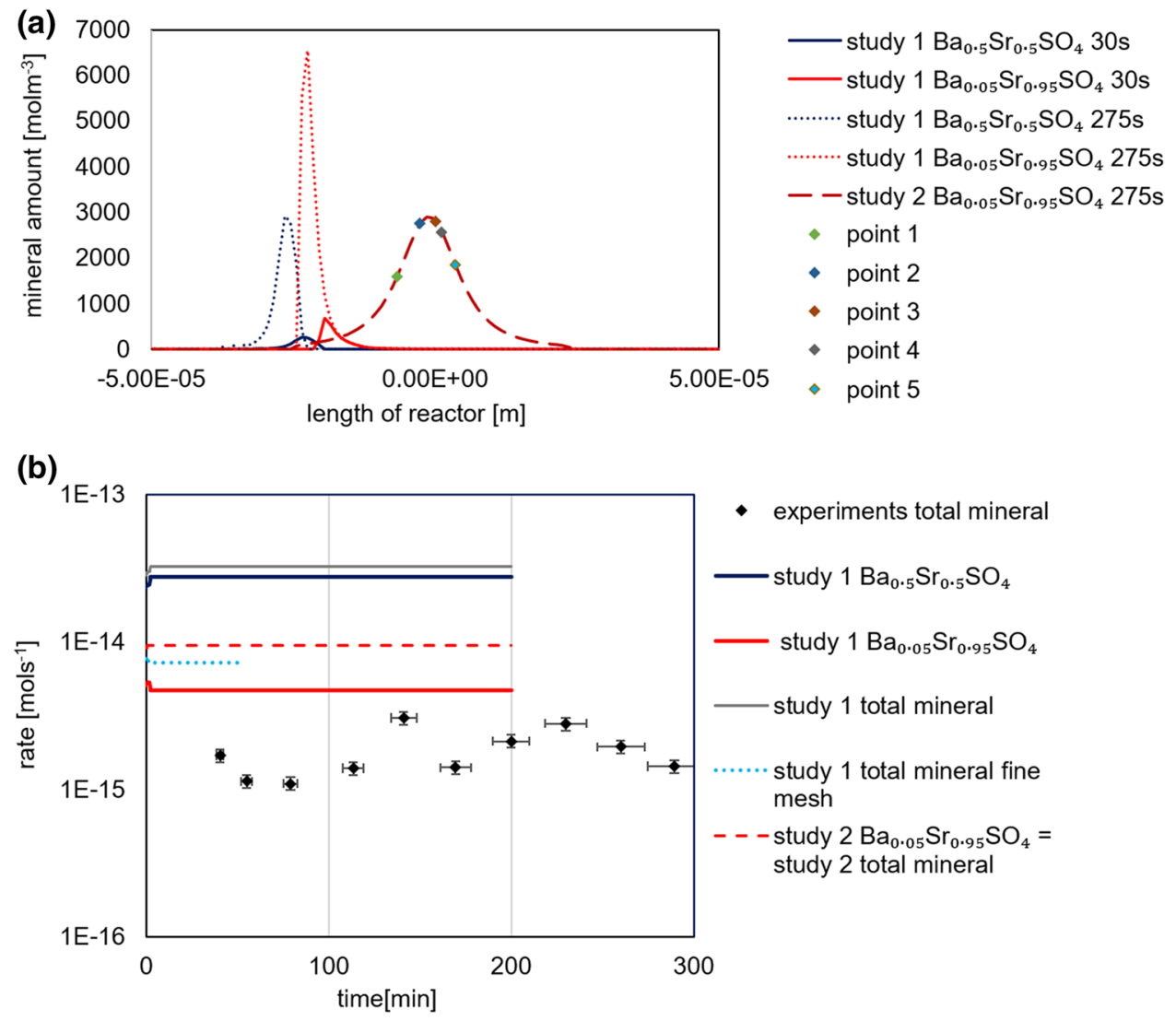

Figure 7. (a) Mineral distribution profiles of the two stoichiometric compositions $\left(\mathrm{Ba}_{0.05} \mathrm{Sr}_{0.95}\right) \mathrm{SO}_{4}$ and $\left(\mathrm{Ba}_{0.5} \mathrm{Sr}_{0.5}\right) \mathrm{SO}_{4}$ across a simulated $1 \mathrm{D}$ reactor for case study 1 at 30 and $275 \mathrm{~s}$ and case study 2 at $275 \mathrm{~s}$ using a discretization of $1 \mu \mathrm{m}$. Points $1-5$ refer to the sampling points used to calculate nucleation and crystallization kinetics in Fig. 9. (b) Comparison of simulated precipitation rates using OGS-GEM with instantaneous precipitation (case study 1) and with kinetic constraints (case study 2) using mesh discretizations of $5 \mu \mathrm{m}$ and $1 \mu \mathrm{m}$ against experimental results (total amount of minerals that precipitated per unit time).

This apparent inconsistency may be explained by taking into account that the nucleation process could induce changes in the local composition of the aqueous solution in direct contact with the crystals. Shortly after nucleation, the formation of an almost pure $\mathrm{BaSO}_{4}$ cluster might lead to a quick local decrease in aqueous $\mathrm{Ba}$ concentration. This would considerably increase the ratio of the aqueous $\mathrm{Sr}$ (injected in excess) to Ba. In a hypothetical case in the vicinity of the aforementioned event and by considering that the $\mathrm{Sr} / \mathrm{Ba}$ ratio in the aqueous solution could increase to 100, the maximum of the stoichiometric saturation function would shift only slightly (Fig. 8d), but the probability of nucleating $\left(\mathrm{Ba}_{0.5} \mathrm{Sr}_{0.5}\right) \mathrm{SO}_{4}$ would dominate over other stoichiometric compositions (Fig. 8e). After the nucleation on the surface of PDMS, further nucleation on the surface of existing sulphates is much faster indicated by the shorter induction time (see Table 1) because of the decrease in surface tension. The formation of $\left(\mathrm{Ba}_{0.93} \mathrm{Sr}_{0.07}\right) \mathrm{SO}_{4}$ is possible and most likely limited in time (takes place at the very early stages only) and space and is therefore not detected at the resolution of our measurement techniques. Moreover, there is ample evidence that demonstrate that the composition of the nuclei is frequently not determined by the maximum supersaturation values alone ${ }^{15}$.

Beside by the stoichiometric saturation function and nucleation kinetics, the composition of the precipitated phase can also be determined by the partition coefficient concept ${ }^{8}$. The partition coefficient concept implies that at very fast precipitation rates, all cations in contact with the growing mineral will be trapped by the layer of newly formed precipitate ${ }^{42}$ such that the composition of the growing phase has the same composition as the surrounding solution, which in our experiment would be $\left(\mathrm{Sr}_{0.9} \mathrm{Ba}_{0.1}\right) \mathrm{SO}_{4}$. The current observation does not follow this trend and it can therefore be inferred that the growth rates are relatively low.

Our results indicate that the composition of the nucleating phase is most likely controlled by nucleation kinetics and can be addressed using Classical Nucleation Theory. Our experimental results are in agreement with the experimental work of Prieto et al. ${ }^{13}$, where $(\mathrm{Ba}, \mathrm{Sr}) \mathrm{SO}_{4}$ zoning is typically bimodal with an expansion of the number of compositions $\left(\left(\mathrm{Ba}_{0.88} \mathrm{Sr}_{0.12}\right) \mathrm{SO}_{4}\right.$ and $\left.\left.\mathrm{Ba}_{0.5} \mathrm{Sr}_{0.5} \mathrm{SO}_{4}\right)\right)$ at higher supersaturation all while keeping the bimodal behaviour.

Towards a mechanistic understanding of the zoning process. The presented continuum scale modelling scenarios cannot reproduce our experimental observations. Case study 1 with instantaneous precipitation 

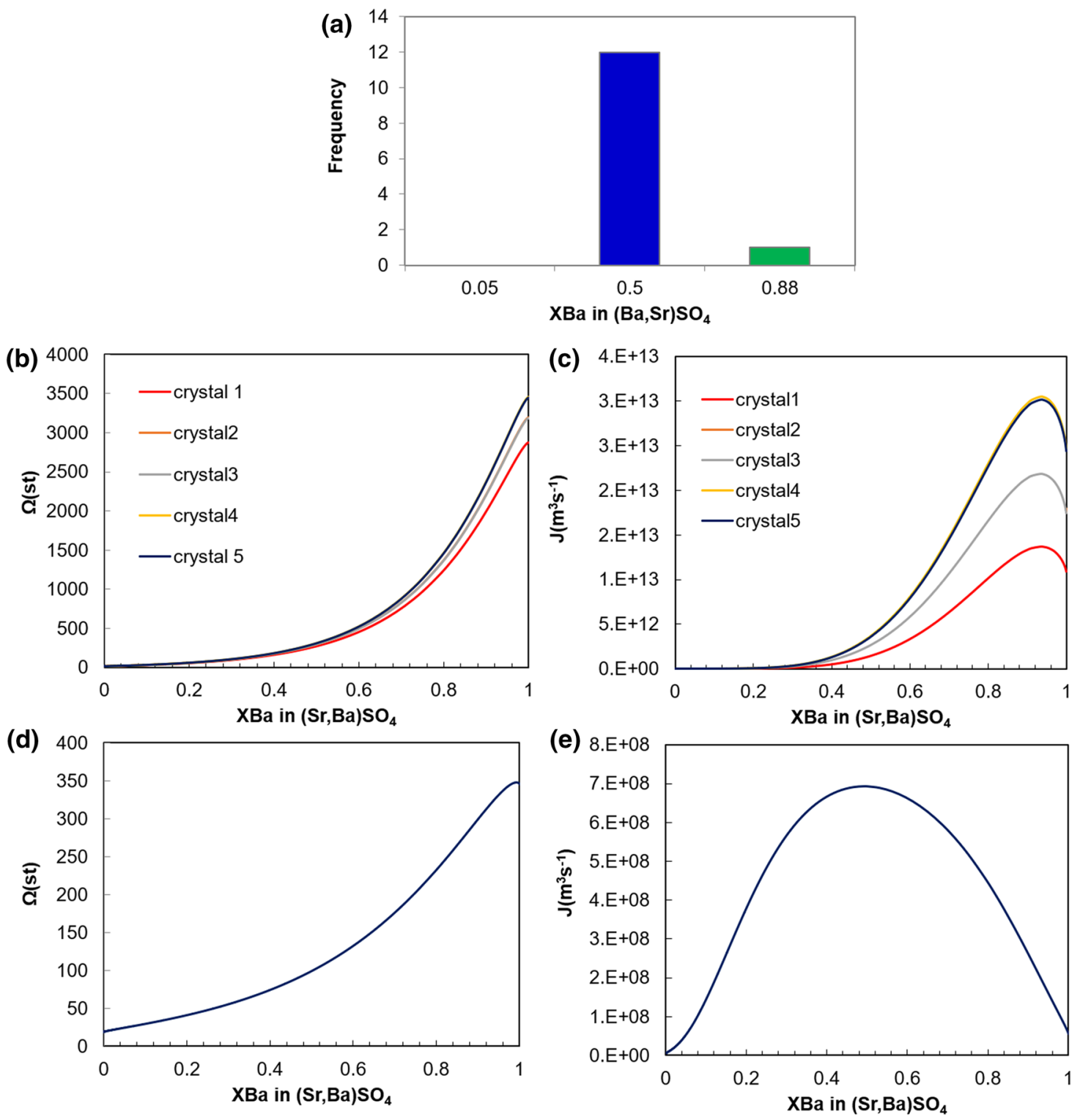

Figure 8. (a) Histograms of the solid solution compositions sampled in the first 5 growth chambers, (b) stoichiometric supersaturations computed for the aqueous solution compositions at the locations where crystals 1-5 in chamber 4 start to nucleate $\left(\mathrm{aSr}^{2+} / \mathrm{aBa}^{2+} \sim 10\right)$ and $(\mathbf{c})$ corresponding nucleation rates, (d) stoichiometric supersaturation function and e) associated nucleation rate for a hypothetical aqueous solution composition with $\mathrm{aSr}^{2+} / \mathrm{aBa}^{2+} \sim 100$.

\begin{tabular}{|l|l|l|l|}
\hline Substrate & Nucleating phase & $\boldsymbol{\sigma}\left(\boldsymbol{X}_{\mathrm{Ba}}\right)$ effective $\left(\mathrm{Jm}^{-2}\right)$ & Calculated induction time $(\mathbf{s})$ \\
\hline PDMS & $\mathrm{Ba}_{0.88} \mathrm{Sr}_{0.12} \mathrm{SO}_{4}$ & 0.077 & 4.6 \\
\hline PDMS & $\mathrm{Ba}_{0.5} \mathrm{Sr}_{0.5} \mathrm{SO}_{4}$ & 0.067 & 35.6 \\
\hline $\mathrm{Ba}_{0.88} \mathrm{Sr}_{0.5} \mathrm{SO}_{4}$ & $\mathrm{Ba}_{0.5} \mathrm{Sr}_{0.5} \mathrm{SO}_{4}$ & 0.017 & $4 \times 10^{-6}$ \\
\hline
\end{tabular}

Table 1. Calculated effective surface tension $\sigma\left(X_{\mathrm{Ba}}\right)$ for different substrates and nucleating phases and calculated induction times ${ }^{41}$.

overestimated the mineral precipitation rates, suggesting that the precipitation of oscillatory zoned crystals of $(\mathrm{Ba}, \mathrm{Sr}) \mathrm{SO}_{4}$ is controlled by kinetics. In case study 2 , which includes the crystal growth rates of minerals, the rate of precipitation was still higher than the experimental rates and the formation of $\mathrm{Ba}_{0.5} \mathrm{Sr}_{0.5} \mathrm{SO}_{4}$ was kinetically suppressed. It can thus be inferred that the precipitation of $\mathrm{Ba}_{0.5} \mathrm{Sr}_{0.5} \mathrm{SO}_{4}$ is controlled by processes that are kinetically slower and which are not included in the presented model, e.g., nucleation processes. 

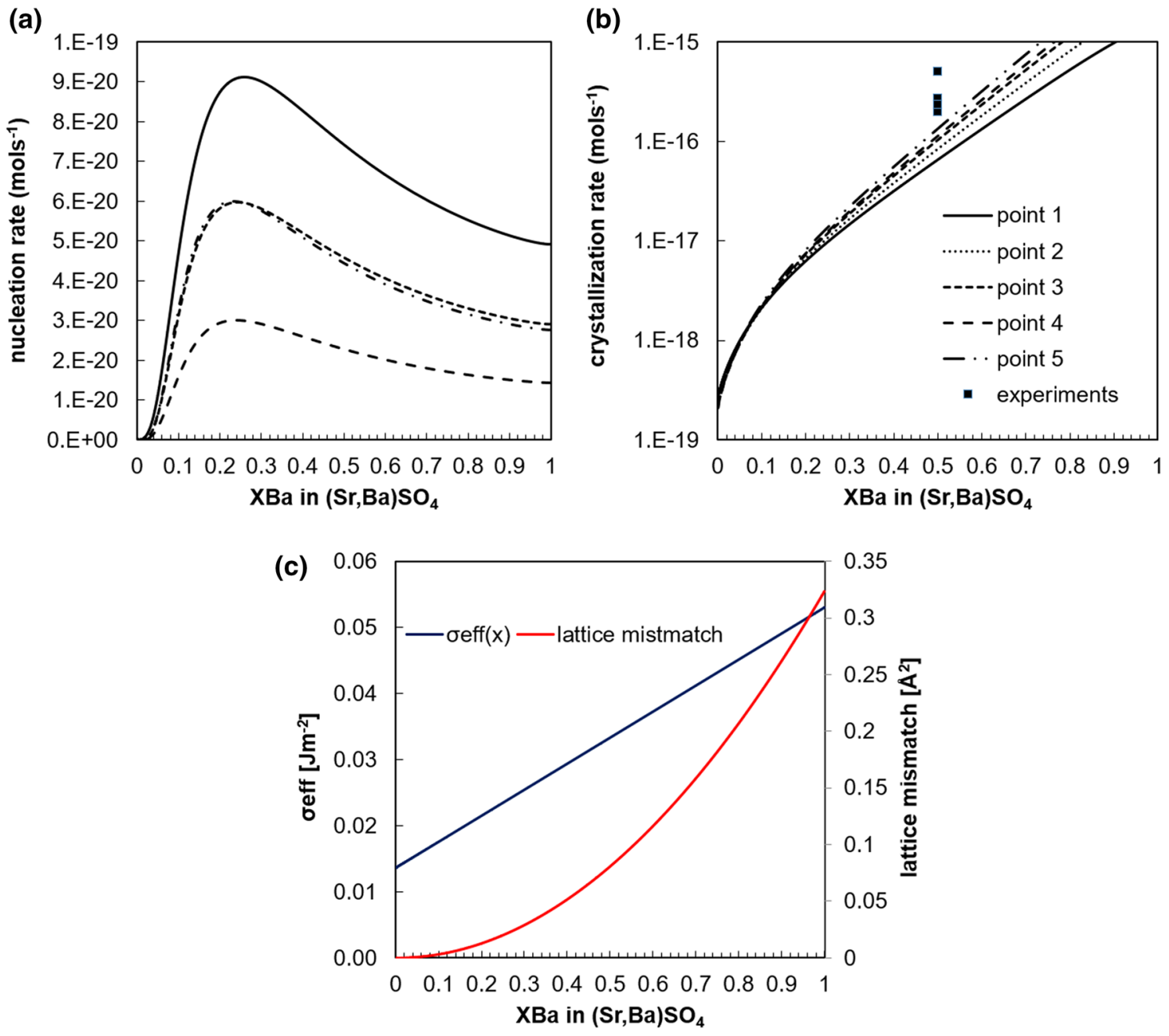

Figure 9. (a) Nucleation rates, (b) associated crystallization rates, and (c) calculated effective surface tension (primary vertical axis) and lattice mismatch (secondary vertical axis) as function of the solid solution series.

To verify this hypothesis, we sampled the simulated aqueous solution composition at different locations (points 1-5 in Fig. 7a in case study 2) to compute the rate of nucleation and crystallization of ( $\mathrm{Ba}, \mathrm{Sr}) \mathrm{SO}_{4}$ solid solutions on the surface of $\mathrm{Ba}_{0.05} \mathrm{Sr}_{0.95} \mathrm{SO}_{4}$ (Fig. 9). The sampled points typically reflect the solution composition after the precipitation of $\mathrm{Ba}_{0.05} \mathrm{Sr}_{0.95} \mathrm{SO}_{4}$. The solution chemistry with $\mathrm{aSr}^{2+} / \mathrm{aBa}^{2+} \sim 2$, indicates that further nucleation of $\mathrm{Ba}_{0.05} \mathrm{Sr}_{0.95} \mathrm{SO}_{4}$ is kinetically hindered but that other compositions with an increased Ba content can nucleate (shown by the maxima of the curves for points 1-5 in Fig. 9a). The precipitation of barium enriched phases is kinetically favoured via nucleation mechanisms. After the precipitation of $\mathrm{Ba}_{0.05} \mathrm{Sr}_{0.95} \mathrm{SO}_{4}$, the nucleation of barium enriched solid solutions becomes competitive enough to allow their precipitation. In fact, the switch to stoichiometric phases other than $\mathrm{Ba}_{0.05} \mathrm{Sr}_{0.95} \mathrm{SO}_{4}$ could be explained by the fact that the nucleation rate of the other stoichiometric phases becomes higher than the rate of crystal growth of $\mathrm{Ba}_{0.05} \mathrm{Sr}_{0.95} \mathrm{SO}_{4}$. This successive nucleation and crystal growth operating at different rates $\left(\mathrm{mol} \mathrm{s}^{-1}\right)$ can also explain the experimentally observed oscillating crystallization rates in Fig. $7 \mathrm{~b}$.

The solution chemistry after the precipitation of $\mathrm{Ba}_{0.05} \mathrm{Sr}_{0.95} \mathrm{SO}_{4}$ favours crystallization of an almost pure barite (Fig. 8b), however, crystallization of solid solutions with compositions with $\mathrm{X}_{\mathrm{Ba}}>0.6$ on the surface of $\mathrm{Ba}_{0.95} \mathrm{Sr}_{0.05} \mathrm{SO}_{4}$ is unlikely and was observed only once and after clogging at the pillars (crystal 3 in chamber 1), where the concentration of aqueous barium can build up in the system. Other factors related to the crystallography of the solid solutions could be decisive for the determination of the composition of the solid solutions that can precipitate. For instance, lattice mismatch (equation S7.1 in supplement S7) that characterizes the difference between the lattice parameters of the growing solid solution and its substrate. Due to significant differences in lattice parameters between the growing phase and the substrate (Fig. 9c), only specific phases can precipitate. Such phenomena are common for the epitaxial growth of sulphate solid solutions 9 . Similarly, the surface tension and therefore the energetic barrier associated with the growth of solid solutions with $\mathrm{X}_{\mathrm{Ba}}>0.6$ on the surface of $\mathrm{Ba}_{0.95} \mathrm{Sr}_{0.05} \mathrm{SO}_{4}$ is relatively large, and is therefore unlikely to occur.

The $1 \mathrm{D}$ continuum approach is limited to describe the processes occurring at the mineral-solution interfaces, nevertheless, it provides strong evidence that oscillatory zoned crystals of $(\mathrm{Ba}, \mathrm{Sr}) \mathrm{SO}_{4}$ are not solely the result of a diffusion induced precipitation process but rather depends on crystallization kinetics. The inclusion 
of crystal growth kinetics alone cannot capture the composition of the precipitating phases but other processes such as nucleation could explain the observed slower precipitation rates. Nucleation mechanisms, although not considered in many reactive transport codes, can be important nanoscale mechanisms influencing macroscale phenomena in subsurface environments ${ }^{43}$.

Another aspect which is expected to play significant role is the spatial heterogeneity especially when the precipitates start to grow. The shape and location of the crystals will alter the diffusion transport fluxes and pathways, while the total reactive surface area (solid/aqueous solution interface) will be continuously evolving, certainly passing through diffusion limited evolution stages before the eventual porosity clogging. In the future, to address the complexity and interplay of mass transport and reaction mechanisms at the pore-level we will focus in the development of a digital twin based on pore-scale lattice Boltzmann framework with machine learning enhanced geochemical speciation. This will enable a systematic assessment of the interplay of mass transport and crystallization kinetics of solid solutions (i.e. the sum of nucleation rate and crystal growth rate) to resolve the physics at the crystal/solution interfaces by taking into account the true crystal heterogeneity as has been done previously for pure celestine $e^{22,23}$ and barite ${ }^{38}$.

\section{Summary}

We developed a lab on a chip experiment that enabled the systematic in-situ assessment of oscillatory zoned crystals of $(\mathrm{Ba}, \mathrm{Sr}) \mathrm{SO}_{4}$ in a confined volume. Our investigations showed that the composition of the nucleating phase can be determined using classical nucleation theory extended to solid solutions. Our numerical and modelling studies were conducted at different levels, each providing significant information for the interpretation of the experiments. The continuum approach modelling, suggested that oscillatory zoning is not the result of the limited diffusion of solutes at least at the first stages. The switch between phases with different stoichiometry is likely caused by competition between nucleation and crystal growth of the two stoichiometric phases. Beside kinetics, other factors such as lattice mismatch or surface tension can also play an important role for the determination of the precipitating phases. In future work, we will integrate crystallization kinetics of solid solutions in our lattice Boltzmann model to create a digital twin of the system to resolve the geochemical processes at the mineral-solution interfaces to overcome the shortcoming of the applied approaches.

Received: 30 July 2021; Accepted: 22 November 2021

Published online: 08 December 2021

\section{References}

1. Heberling, F., Schild, D., Degering, D. \& Schäfer, T. How well suited are current thermodynamic models to predict or interpret the composition of (Ba, Sr)SO4 solid-solutions in geothermal scalings?. Geotherm. Energy 358, 1-16 (2017).

2. Besançon, C. et al. The role of barite in the post-mining stabilization of radium-226: A modeling contribution for sequential extractions. Minerals https://doi.org/10.3390/min 10060497 (2020).

3. Zhang, T., Gregory, K., Hammack, R. \& Vidic, R. Co-precipitation of radium with barium and strontium sulfate and its impact on the fate of radium during treatment of produced water from unconventional gas extraction. Environ. Sci. Technol. 48, 4596-4603 (2014).

4. Ling, F. et al. Nanospectroscopy captures nanoscale compositional zonation in barite solid solutions. Sci. Rep. 8, 1-11 (2018).

5. Heather, H., Ling, F. T. \& Peters, C. Metals coprecipitation with barite: Nano-XRF observation of enhanced strontium incorporation. Environ. Eng. Sci. 37(4), 235-245 (2020).

6. Poonoosamy, J. et al. Combination of MRI and SEM to assess changes in the chemical properties and permeability of porous media due to barite precipitation. Minerals 10(3), 226. https://doi.org/10.3390/min10030226 (2020).

7. Brandt, F., Klinkenberg, M., Poonoosamy, J., Weber, J. \& Bosbach, D. The effect of ionic strength and Sraq upon the uptake of Ra during the recrystallization of barite. Minerals 8, 502 (2018).

8. Curti, E. et al. Modelling Ra-baryte nucleation/precipitation kinetics at the pore scale. Eur. J. Mineral. 31, 247-262 (2019).

9. Klinkenberg, M. et al. The solid solution-aqueous solution system ( $\mathrm{Sr}, \mathrm{Ba}, \mathrm{Ra}) \mathrm{SO} 4+\mathrm{H} 2 \mathrm{O}$ : A combined experimental and theoretical study of phase equilibria at Sr-rich compositions. Chem. Geol. 497, 1-17 (2018).

10. Heberling, F., Metz, V., Böttle, M., Curti, E. \& Geckeis, H. Barite recrystallization in the presence of 226Ra and 133Ba. Geochim. Cosmochim. Acta 232, 124-139 (2018).

11. Vinograd, V. et al. Thermodynamics of the solid solution-Aqueous solution system (Ba, Sr, Ra)SO4 + H2O: I. The effect of strontium content on radium uptake by barite. Appl. Geochem. 89, 54-74 (2018).

12. Vinograd, V. et al. Thermodynamics of the solid solution-Aqueous solution system (Ba, Sr, Ra)SO4 + H2O: II. Radium retention in barite-type minerals at elevated temperatures. Appl. Geochem. 93, 190-208 (2018).

13. Prieto, M., Fernández-González, A., Putnis, A. \& Fernández-Díaz, L. Nucleation, growth, and zoning phenomena in crystallizing ( $\mathrm{Ba}, \mathrm{Sr}) \mathrm{CO} 3, \mathrm{Ba}(\mathrm{SO} 4, \mathrm{CrO} 4),(\mathrm{Ba}, \mathrm{Sr}) \mathrm{SO} 4$, and $(\mathrm{Cd}, \mathrm{Ca}) \mathrm{CO} 3$ solid solutions from aqueous solutions. Geochim. Cosmochim. Acta 61, 3383-3397 (1997).

14. Weber, J. et al. Unraveling the effects of strontium incorporation on barite growth-In situ and ex situ observations using multiscale chemical imaging. Cryst. Growth Des. 18, 5521-5533 (2018).

15. Prieto, M. Thermodynamics of solid solution-aqueous solution systems. Rev. Mineral. Geochem. 70, 47-85 (2009).

16. Putnis, A., Fernandez-Diaz, L. \& Prieto, M. Experimentally produced oscillatory zoning in the (Ba, $\mathrm{Sr}) \mathrm{SO} 4$ solid solution. Nature 358, 743-745 (1992).

17. Pina, C. M., Enders, M. \& Putnis, A. The composition of solid solutions crystallising from aqeous solutions: The influence of supersaturation and grwoth mechanisms. Chem. Geol. 168, 195-210 (2000).

18. L'Heureux, I. \& Katsev, S. Oscillatory zoning in a (ba, Sr)SO4 solid solution: Macroscopic and cellular automata models. Chem. Geol. 225(3-4), 230-243 (2006).

19. Poonoosamy, J. et al. (2020) Microfluidic flow-through reactor and 3D Raman imaging for in situ assessment of mineral reactivity in porous and fractured porous media. Lab Chip. 20(14), 2562-2571. https://doi.org/10.1039/D0LC00360C

20. Prasianakis, N. I., Gatschet, M., Abbasi, A. \& Churakov, S. V. Upscaling strategies of porosity-permeability correlations in reacting environments from pore-scale simulations. Geofluids 2018, 1-18 (2018).

21. Churakov, S. V. \& Prasianakis, N. I. Review of the current status and challenges for a holistic process-based description of mass transport and mineral reactivity in porous media. Am. J. Sci. 318, 921-948 (2018). 
22. Poonoosamy, J. et al. A microfluidic experiment and pore scale modelling diagnostics for assessing mineral precipitation and dissolution in confined spaces. Chem. Geol. 528, 119264 (2019).

23. Prasianakis, N. I. et al. Neural network based process coupling and parameter upscaling in reactive transport simulations. Geochim. Cosmochim. Acta 291, 126-143 (2020).

24. Noguera, C., Fritz, B. \& Clement, F. "Kinetic of precipitation of non ideal solid solutions in liquid environment solid solution. Chem. Geol. 431, 20-35 (2016).

25. Everall, N. J. Confocal Raman Microscopy: Performance, Pitfalls, and Best Practice, in 50 Years of SAS: Looking to the Future with Vibrational Spectroscopy (New Orleans, Louisiana, 2008).

26. Talla, D. \& Wildner, M. Investigation of the kieserite-szomolnokite solid-solution series, (Mg, Fe)SO4.H2O, with relevance to Mars: Crystal chemistry, FTIR, and Raman spectroscopy under ambient and martian temperature conditions. Am. Miner. 104(12), $1732-1749$ (2019)

27. Chen, Y.-H., Huang, E. \& Yu, S.-C. High-pressure Raman study on the BaSO4-SrSO4 series. Solid State Commun. 45-46, 2050-2052 (2009).

28. Astilleros, J. M., Pina, C., Fernandez-Diaz, L. \& Putnis, A. Spersaturation functions in binary solid solution-aqeous solution systems. Geochim. Cosmochim. Acta 67(9), 1601-1608 (2003).

29. Hummel, W., Berner, U., Curti, E., Pearson, F. \& Thoenen, T. Nagra/PSI chemical thermodynamic data base 01/01. Radiochim. Acta 90, 1 (2002).

30. Thomson, J. \& Waldbaum, D. Analysis of the two-phase region halite-sylvite in the system NaCl-KCl. Geochim. Cosmochim. Acta 33, 671-690 (1969).

31. Nielsen, A. \& Sohnel, O. Interfacial tensions electrolyte crystal-aqeous solution nucleation data. J. Cryst. Growth 11, 233-242 (1971)

32. Ruiz-Aguido, C., Putnis, C. V. \& Encarnacion Ruiz-Aguido, A. P. The influence of pH on barite nucleation and growth. Chem. Geol. 391, 7-18 (2015).

33. Poonoosamy, J. et al. Barite precipitation following celestite dissolution in a porous medium: A SEM/BSE and $\mu$-XRD/XRF study. Geochimica et Cosmochimica Acta 182, 131-144. https://doi.org/10.1016/j.gca.2016.03.011 (2016).

34. Prieto, M. Nucleation and supersaturation in porous media. Mineral. Mag. 78, 1437-1447 (2014).

35. Bosbach, D. Linking molecular-scale barite precipitation mechanisms with macroscopic crystal growth rates. In Water-Rock Interactions, Ore deposits and Environmental Geochemistry: A tribute to David A Crerar (eds Hellmann, R. \& Wood, S. A.) 97-110 (The Geochemical Society, Washington, D.C., 2002).

36. Marty, N. et al. A database of dissolution and precipitation rates for clay-rocks minerals. Appl. Geochem. 55, 108-118 (2015).

37. Hamdona, S. \& Hamza, S. Influence of polyphosphonates on the precipitation of strontium sulfate (celestite) from aqueous solutions. J. Taibah Univ. Sci. 2, 36-43 (2009).

38. Prasianakis, N. I., Curti, E., Kosakowski, G., Poonoosamy, J. \& Churakov, S. V. Deciphering pore-level precipitation mechanisms. Sci. Rep. 7, 13765 (2017).

39. Poonoosamy, J. et al. Effects of solution supersaturation on barite precipitation in porous media and consequences on permeability: Experiments and modelling. Geochim. Cosmochim. Acta 270, 43-60 (2020).

40. Poonoosamy, J. et al. Benchmarking of reactive transport codes for $2 \mathrm{D}$ simulations with mineral dissolution-precipitation reactions and feedback on transport parameters. Comput. Geosci. 25, 1-22 (2018).

41. Kashchiev, D. \& van Rosmalen, G. M. Review: Nucleation in solutions revisited. Cryst. Res. Technol. 38(7-8), 555-574 (2003).

42. Felmy, A., Rai, D. \& Moore, D. A. The solubility of (ba, Sr)SO4 precipitates: Thermodynamic equilibrium and reaction path analysis. Geochim. Cosmochim. Acta 225(3-4), 230-243 (1993).

43. Li, Q., Steefel, C. I. \& Jun, Y. Incorporating nanoscale effects into a continuum-scale reactive transport model for CO2-deteriorated cement. Environ. Sci. Technol. 51(18), 10861-10871 (2017).

\section{Acknowledgements}

The research leading to these results has received funding from the German Federal Ministry of Education and Research (BMBF, Grant agreement 02NUK053A) and from the Initiative and Networking Fund of the Helmholtz Association (HGF Grant SO-093) within the iCross project, and from the Swiss National Science Foundation (SNSF, Project No.: SNF-200021-172618). This project has received funding from the European Union's Horizon 2020 research and innovation program under Grant agreement No 847593 within workpackages DONUT and FUTURE. JP is thankful to Alexander Gruggenberger and Alina Burmeister for the design and fabrication of the micromodel and to Juliane Weber for sharing her datasets and expertise on her results published in Weber et al. $^{35}$. Last but not the least, JP thanks Martina Klinkenberg and Felix Brandt for providing previously synthesized and characterized by SEM-EDX solid solution of $(\mathrm{Ba}, \mathrm{Sr}) \mathrm{SO}_{4}$ for Raman measurements in supplements $\mathrm{S} 8$.

\section{Author contributions}

JP designed, conducted the experiments and processed the experimental data. JP conducted the continuum scale modelling and MM did the pore scale modelling. JP, EC, NP and MM discussed the experimental results, addressed the theoretical and modelling aspects and wrote the manuscript. DB, GD and JP applied for iCross funding. SC contributed in the discussions of the pore scale modelling results. TG discussed the Raman data. All authors reviewed and approved the manuscript.

\section{Funding}

Open Access funding enabled and organized by Projekt DEAL.

\section{Competing interests}

The authors declare no competing interests.

\section{Additional information}

Supplementary Information The online version contains supplementary material available at https://doi.org/ 10.1038/s41598-021-02840-9.

Correspondence and requests for materials should be addressed to J.P.

Reprints and permissions information is available at www.nature.com/reprints. 
Publisher's note Springer Nature remains neutral with regard to jurisdictional claims in published maps and institutional affiliations.

(c) (1) Open Access This article is licensed under a Creative Commons Attribution 4.0 International License, which permits use, sharing, adaptation, distribution and reproduction in any medium or format, as long as you give appropriate credit to the original author(s) and the source, provide a link to the Creative Commons licence, and indicate if changes were made. The images or other third party material in this article are included in the article's Creative Commons licence, unless indicated otherwise in a credit line to the material. If material is not included in the article's Creative Commons licence and your intended use is not permitted by statutory regulation or exceeds the permitted use, you will need to obtain permission directly from the copyright holder. To view a copy of this licence, visit http://creativecommons.org/licenses/by/4.0/.

(C) The Author(s) 2021 